\title{
HIGH ORDER THINKING SKILL DALAM PEMBENTUKAN KARAKTER SISWA SEKOLAH DASAR DI ERA INDUSTRI 4.0
}

\author{
Husni Mubarok \\ IAIN Kudus, Kudus, Indonesia \\ husnimubarok@iainkudus.ac.id
}

\begin{abstract}
The 2013 curriculum emphasizes the importance of High Order Thinking Skills and developing character values. It aims to balance intellectual ability and character in accordance with national education goals. This study aims to discuss a) the concept of High Order Thinking Skill, b) the concept of character building, and c) analysis of High Order Thinking Skills for character building elementary school students. The method used is library research with a qualitative approach. The research method is content analysis. The results of this study are 1) Higher Order Thinking Skill is a process of thinking critically, creatively, analytically to information and data in solving problems with cognitive, affective, and psychomotor skills that become a unity in the learning and teaching process. 2) Character is a way of thinking and behaving that characterizes each individual to live and work together. 3) The application of HOTS in the industrial era 4.0 using 4Cs Learning (critical thinking, communication, collaboration, and creativity) are four skills to foster character in elementary school students.
\end{abstract}

Keywords: HOTS, Character, Primary School

\begin{abstract}
Abstrak
Kurikulum 2013 mengedepankan pentingnya High Order Thinking Skill dan mengembangkan nilai-nilai karakter. Hal ini bertujuan agar terjadi keseimbangan antara kemampuan
\end{abstract}


intelektual dan karakter sesuai dengan tujuan pendidikan nasional. Penelitian ini bertujuan untuk membahas a) konsep High Order Thinking Skill, b) konsep pembentukan karakter, dan c) analisis High Order Thinking Skill dalam pembentukan karakter siswa sekolah dasar. Metode yang digunakan adalah metode library research dengan pendekatan kualitatif. Metode penelitian yang digunakan pada penelitian ini adalah analisis isi. Hasil dari penelitian ini adalah 1) Higher Order Thinking Skill adalah proses berpikir secara kritis, kreatif, analitis terhadap informasi dan data dalam memecahkan permasalahan dengan keterampilan berpikir ranah kognitif, afektif, dan psikomotor yang menjadi satu kesatuan dalam proses belajar dan mengajar. 2) Karakter adalah cara berpikir dan berperilaku yang menjadi ciri khas tiap individu untuk hidup dan bekerja sama. 3) Penerapan HOTS di era industri 4.0 menggunakan Pembelajaran 4Cs (critical thinking, communication, collaboration, and creativity) adalah empat keterampilan untuk menumbuhkan karakter pada siswa sekolah dasar.

Kata Kunci: HOTS, Karakter, Sekolah Dasar

\section{A. Pendahuluan}

Undang-Undang Nomor 20 Tahun 2003 tentang Sistem Pendidikan Nasional pasal 57 menyatakan bahwa evaluasi dilakukan dalam rangka pengendalian mutu pendidikan terhadap siswa, lembaga, dan program pendidikan pada jalur formal dan non formal untuk semua jenjang, satuan, dan jenis pendidikan. Ujian Nasional (UN) dan Ujian Sekolah Berstandar Nasional (USBN) merupakan bagian yang tidak dapat dipisahkan dari sistem pendidikan nasional. UN adalah sistem evaluasi standar pendidikan dasar dan menengah secara nasional dan persamaan mutu tingkat pendidikan antar daerah yang dilakukan oleh Pusat Penilaian Pendidikan. UN digunakan sebagai bagian dari evaluasi, Indonesia melakukan benchmark internasional dengan mengikuti Trends in International Mathematics and Science Study (TIMSS) dan Programme for International Student Assessment (PISA). 
Hasil TIMMS tahun 2015 untuk kelas IV sekolah dasar, Indonesia mendapatkan rata-rata nilai 397 dan menempati peringkat 4 terbawah dari 43 negara yang mengikuti TIMMS (TIMMS International Database, 2015). Sekitar 75\% item yang diujikan dalam TIMSS telah diajarkan di kelas IV Sekolah Dasar dan hal tersebut lebih tinggi dibanding Korea Selatan yang hanya $68 \%$, namun kedalaman pemahamannya masih kurang. Dari sisi lama pembelajaran siswa Sekolah Dasar dan jumlah jam pelajaran matematika, Indonesia termasuk paling lama di antara negara lainnya, tetapi kualitas pembelajarannya masih perlu ditingkatkan. Sementara untuk PISA tahun 2015, Indonesia mendapatkan ratarata nilai 403 untuk sains (peringkat ketiga dari bawah), 397 untuk membaca (peringkat terakhir), dan 386 untuk matematika (peringkat kedua dari bawah) dari 72 negara yang mengikuti (PISA Database OECD, 2015). Meskipun peningkatan capaian Indonesia cukup signifikan dibandingkan hasil tahun 2012, namun capaian secara umum masih di bawah rerata negara OECD (Organisation for Economic Co-operation and Development). Bila peningkatan ini terus dipertahankan, maka pada tahun 2030 capaian Indonesia diprediksi dapat menyamai OECD.

Hasil pengukuran capaian siswa berdasar UN ternyata selaras dengan capaian PISA maupun TIMSS. Hasil UN tahun 2018 menunjukkan bahwa siswa masih lemah dalam keterampilan berpikir tingkat tinggi (Higher Order Thinking Skill) seperti menalar, menganalisa, dan mengevaluasi. Oleh karena itu salah satu upaya Kementerian Pendidikan dan Kebudayaan melalui Direktorat Jenderal Guru dan Tenaga Kependidikan (Ditjen GTK) untuk meningkatkan kualitas pembelajaran dikembangkan soal-soal dan pembelajaran yang berorientasi kepada keterampilan berpikir tingkat tinggi (Higher Order Thinking Skill) agar terdorong kemampuan berpikir kritisnya.

Kurikulum 2013 selain mengedepankan pentingnya keterampilan berpikir tingkat tinggi juga menginginkan agar pembelajaran ikut mengembangkan nilai-nilai karakter. Hal ini bertujuan agar terjadi keseimbangan antara kemampuan intelektual 
dan karakter, sebagaimana tertuang dalam tujuan pendidikan nasional dalam Undang-Undang Nomor 20 Tahun 2003. Dalam pendidikan karakter pentingnya menekankan tiga komponen karakter yang saling berhubungan yaitu moral knowing, moral feeling dan moral action (Lickona, 1991). Dalam rangka lebih memperkuat pelaksanaan pendidikan karakter, dalam Kurikulum 2013 telah teridentifikasi 18 nilai yang bersumber dari agama, Pancasila, budaya, dan tujuan pendidikan nasional, yaitu: jujur, toleransi, disiplin, kerja keras, kreatif, mandiri, demokratis, rasa ingin tahu, semangat kebangsaan, cinta tanah air, menghargai prestasi, bersahabat/komunikatif, cinta damai, gemar membaca, peduli lingkungan, peduli sosial, tanggung jawab, dan religius (Kemendiknas, 2011). Adapun strategi yang dapat digunakan untuk mengembangkan pendidikan karakter meliputi keteladanan, intervensi, pembiasaan yang dilakukan secara konsisten, dan penguatan (Masruri, 2012). Untuk mendukung keterlaksanaan strategi tersebut dalam pembelajaran, maka diperlukan suatu model pembelajaran yang memuat pendidikan karakter sekaligus berorientasi pada HOTS. Namun, kemampuan berpikir siswa juga belum diarahkan pada level keterampilan berpikir yang lebih tinggi, diantaranya adalah kemampuan berpikir kritis dan kreatif dalam menyelesaikan masalah. Berdasarkan permasalahan yang diungkapkan, penulis akan membahas a) konsep High Order Thinking Skill, b) konsep pembentukan karakter, dan c) analisis High Order Thinking Skill dalam pembentukan karakter siswa sekolah dasar.

\section{B. Pembahasan}

\section{Metode Penelitian}

Metode yang digunakan dalam penelitian ini adalah metode library research dengan pendekatan kualitatif. Metode penelitian yang digunakan pada penelitian ini adalah analisis isi. Analisi isi merupakan suatu studi yang menggabungkan hasil banyak studi orisinal, sistematis, terencana, observasi retrospektif, dengan analisis statistika yang formal.

Metode ini dilaksanakan melalui lima tahap, yaitu (1) Pengumpulan data; (2) Pertanyaan penelitian; (3) Hipotesis yang 
akan diuji; (4) Penyajian data dan (5) Penarikan kesimpulan. Sumber data dalam artikel ini adalah jurnal dan buku yang berkaitan dengan High Order Thinking Skill dan karakter.

\section{Hasil Penelitian}

\section{a. Konsep High Order Thinking}

Higher Order Thinking Skill (HOTS) adalah keterampilan berfikir tingkat tinggi yang menuntut pemikiran secara kritis, kreatif, analitis terhadap informasi dan data dalam memecahkan permasalahan (Barratt, 2014). Berfikir tingkat tinggi merupakan jenis pemikiran yang mencoba mengeksplorasi pertanyaan-pertanyaan mengenai pengetahuan yang ada terkait isu-isu yang tidak didefinisikan dengan jelas.

Menurut beberapa ahli, definisi keterampilan berpikir tingkat tinggi salah satunya dari Resnick (1987) adalah proses berpikir kompleks dalam menguraikan materi, membuat kesimpulan, membangun representasi, menganalisis, dan membangun hubungan dengan melibatkan aktivitas mental yang paling dasar. Keterampilan ini juga digunakan untuk menggarisbawahi berbagai proses tingkat tinggi menurut jenjang taksonomi Bloom.

Menurut Bloom, keterampilan dibagi menjadi dua bagian. Pertama adalah keterampilan tingkat rendah yang penting dalam proses pembelajaran, yaitu mengingat (remembering), memahami (understanding), dan menerapkan (applying), dan kedua adalah yang diklasifikasikan ke dalam keterampilan berpikir tingkat tinggi berupa keterampilan menganalisis (analysing), mengevaluasi (evaluating), dan mencipta (creating).

Keterampilan berpikir tingkat tinggi erat kaitannya dengan keterampilan berpikir sesuai dengan ranah kognitif, afektif, dan psikomotor yang menjadi satu kesatuan dalam proses belajar dan mengajar.

1. Ranah Kognitif

Ranah kognitif meliputi kemampuan dari siswa dalam mengulang atau menyatakan kembali konsep/prinsip yang telah dipelajari dalam proses pembelajaran yang telah

Elementary Vol. 7 No. 2 Juli-Desember 2019 
didapatnya. Proses ini berkenaan dengan kemampuan dalam berpikir, kompetensi dalam mengembangkan pengetahuan, pengenalan, pemahaman, konseptualisasi, penentuan dan penalaran. Tujuan pembelajaran pada ranah kognitif menurut Bloom merupakan segala aktivitas pembelajaran menjadi 6 tingkatan sesuai dengan jenjang terendah sampai tertinggi.

Tabel 1. Proses kognitif sesuai dengan level kognitif bloom

\begin{tabular}{|c|c|c|c|}
\hline \multicolumn{3}{|c|}{ Proses Kognitif } & \multirow{2}{*}{$\begin{array}{l}\text { Definisi } \\
\text { Mengambil pengetahuan yang relevan dari } \\
\text { ingatan }\end{array}$} \\
\hline $\mathrm{C} 1$ & LOTS & Mengingat & \\
\hline $\mathrm{C} 2$ & & Memahami & $\begin{array}{l}\text { Membangun arti dari proses pembelajaran, } \\
\text { termasuk komunikasi lisan, tertulis, dan } \\
\text { gambar }\end{array}$ \\
\hline $\mathrm{C} 3$ & & $\begin{array}{l}\text { Menerapkan/ } \\
\text { Mengaplikasikan }\end{array}$ & $\begin{array}{l}\text { Melakukan atau menggunakan prosedur di } \\
\text { dalam situasi yang tidak biasa }\end{array}$ \\
\hline $\mathrm{C} 4$ & HOTS & Menganalisis & $\begin{array}{l}\text { Memecah materi ke dalam bagian- } \\
\text { bagiannya dan menentukan bagaimana } \\
\text { bagian-bagian itu terhubungkan } \\
\text { antarbagian dan ke struktur atau tujuan } \\
\text { keseluruhan }\end{array}$ \\
\hline C5 & & $\begin{array}{l}\text { Menilai/ } \\
\text { Mengevaluasi }\end{array}$ & $\begin{array}{l}\text { Membuat pertimbangan berdasarkan } \\
\text { kriteria atau } \\
\text { standar }\end{array}$ \\
\hline C6 & & $\begin{array}{l}\text { Mengkreasi/ } \\
\text { Mencipta }\end{array}$ & $\begin{array}{l}\text { Menempatkan unsur-unsur secara } \\
\text { bersama-sama } \\
\text { untuk membentuk keseluruhan secara } \\
\text { koheren } \\
\text { atau fungsional; menyusun kembali unsur- } \\
\text { unsur ke } \\
\text { dalam pola atau struktur baru }\end{array}$ \\
\hline
\end{tabular}


2. Ranah Afektif

Kartwohl \& Bloom juga menjelaskan bahwa selain kognitif, terdapat ranah afektif yang berhubungan dengan sikap, nilai, perasaan, emosi serta derajat penerimaan atau penolakan suatu objek dalam kegiatan pembelajaran dan membagi ranah afektif menjadi 5 kategori, yaitu seperti pada tabel 2

Tabel 2. Ranah Afektif

\begin{tabular}{lcl}
\hline \multicolumn{2}{c}{ Proses Afektif } & \multicolumn{1}{c}{ Definisi } \\
\hline A1 & Penerimaan & $\begin{array}{l}\text { Semacam kepekaan dalam menerima rangsangan atau } \\
\text { stimulasi dari luar yang datang pada diri siswa }\end{array}$ \\
\hline A2 & Menanggapi & $\begin{array}{l}\text { suatu sikap yang menunjukkan adanya partisipasi aktif } \\
\text { untuk mengikutsertakan dirinya dalam fenomena } \\
\end{array}$ \\
& & $\begin{array}{l}\text { tertentu dan membuat reaksi terhadapnya dengan salah } \\
\text { satu cara. }\end{array}$ \\
\hline A3 & Penilaian & $\begin{array}{l}\text { Memberikan nilai, penghargaan dan kepercayaan } \\
\text { terhadapsuatu gejala atau stimulus tertentu. }\end{array}$ \\
\hline A4 & Mengelola & $\begin{array}{l}\text { Konseptualisasi nilai-nilai menjadi sistem nilai, serta } \\
\text { pemantapan dan prioritas nilai yang telah dimiliki. }\end{array}$ \\
\hline A5 & Karakterisasi & $\begin{array}{l}\text { Keterpaduan semua sistem nilai yang telah dimiliki } \\
\text { seseorangyang mempengaruhi pola kepribadian dan } \\
\end{array}$ \\
& &
\end{tabular}

3. Ranah Psikomotor

Keterampilan proses psikomotor merupakan keterampilan dalam melakukan pekerjaan dengan melibatkan anggota tubuh yang berkaitan dengan gerak fisik yang terdiri dari gerakan refleks, keterampilan pada gerak dasar, perseptual, ketepatan, keterampilan kompleks, ekspresif dan interperatif. Keterampilan proses psikomotor dapat dilihat pada tabel 3. 
Tabel 3. Ranah Psikomotor

\begin{tabular}{|c|c|c|}
\hline \multicolumn{2}{|c|}{ Proses Psikomotor } & Definisi \\
\hline $\mathrm{P} 1$ & Imitasi & Imitasi berarti meniru tindakan seseorang \\
\hline $\mathrm{P} 2$ & Manipulasi & $\begin{array}{l}\text { Manipulasi berarti melakukan keterampilan atau } \\
\text { menghasilkan produk dengan cara dengan mengikuti } \\
\text { petunjuk umum, bukan berdasarkan observasi. Pada } \\
\text { kategori ini, siswa dipandu melalui instruksi untuk } \\
\text { melakukan keterampilan tertentu. }\end{array}$ \\
\hline P3 & Presisi & $\begin{array}{l}\text { Presisi berarti secara independen melakukan } \\
\text { keterampilan atau menghasilkan produk dengan akurasi, } \\
\text { proporsi, dan ketepatan. Dalam bahasa sehari-hari, } \\
\text { kategori ini dinyatakan sebagai "tingkat mahir". }\end{array}$ \\
\hline P4 & Artikulasi & $\begin{array}{l}\text { Artikulasiartinyamemodifikasiketerampilanatauproduk } \\
\text { agar sesuai dengan situasi baru, atau menggabungkan } \\
\text { lebih dari satu keterampilan dalam urutan harmonis dan } \\
\text { konsisten. }\end{array}$ \\
\hline P5 & Naturalisasi & $\begin{array}{l}\text { Naturalisasi artinya menyelesaikan satu atau lebih } \\
\text { keterampilan dengan mudah dan membuat keterampilan } \\
\text { otomatis dengan tenaga fisik atau mental yang ada. } \\
\text { Pada kategori ini, sifat aktivitas telah otomatis, sadar } \\
\text { penguasaan aktivitas, dan penguasaan keterampilan } \\
\text { terkait sudah pada tingkat strategis (misalnya dapat } \\
\text { menentukan langkah yang lebih efisien). }\end{array}$ \\
\hline
\end{tabular}

\section{b. Konsep Pembentukan Karakter}

Ditinjau dari sudut etimologi, kata "karakter" atau dalam bahasa Inggris disebut "character" dan bahasa Yunani "charassein" (Guralnik,1986), artinya mengukir hingga terbentuk sebuah pola, dapat pula diartikan sebagai "pola perilaku moral individu". Karenanya, untuk mendidik anak agar memiliki karakter diperlukan proses 'mengukir', yakni pengasuhan dan pendidikan yang tepat. Menurut Wynne, istilah karakter diambil dari bahasa Yunani pula yang berarti 'tomark' atau menandai. Istilah ini lebih fokus pada tindakan atau tingkah laku. Wynne mengatakan bahwa ada dua pengertian tentang karakter. Pertama, ia menunjukkan bagaimana seseorang bertingkah laku. Apabila seseorang berperilaku tidak jujur, kejam, atau rakus, tentulah orang tersebut memanifestasikan perilaku buruk/jelek. Sebaliknya, apabila seseorang berperilaku jujur, 
suka menolong, tentulah orang tersebut memanifestasikan karakter mulia. Kedua, istilah karakter erat kaitannya dengan'personality'. Seseorang baru bisa disebut' orang yang berkarakter'(a person of character) apabila tingkah lakunya sesuai kaidah moral.

Karakter merupakan ciri khas seseorang atau sekelompok orang yang mengacu pada serangkaian sikap (attitudes), perilaku (behaviors), motivasi (motivations), dan keterampilan (skills) sebagai manifestasi dari nilai, kemampuan, kapasitas moral, dan ketegaran dalam menghadapi kesulitan dan tantangan. Karakter mengandung nilai-nilai yang khasbaik (tahu nilai kebaikan, mau berbuat baik, nyata berkehidupan baik, dan berdampak baik terhadap lingkungan) yang terpateri dalam diri dan terejawantahkan dalam perilaku. Karakter merupakan kemampuan individu untuk mengatasi keterbatasan fisiknya dan kemampuannya untuk membaktikan hidupnya pada nilai-nilai kebaikan yang bermanfaat bagi diri sendiri dan orang lain. Dengan demikian, karakter yang kuat membentuk individu menjadi pelaku perubahan bagi diri sendiri dan masyarakat sekitarnya (Albertus, 2015). Karakter secara koheren memancar dari hasil olah pikir, olah hati, olah raga, serta olah rasa dan karsa seseorang atau sekelompok orang.

Karakter adalah watak,tabiat, akhlak, atau kepribadian seseorang yang terbentuk dari hasil internalisasi berbagai kebajikan (virtues) yang diyakini dan digunakan sebagai landasan untuk cara pandang, berpikir, bersikap, dan bertindak. Kebajikan terdiri atas sejumlah nilai, moral, dan norma, seperti jujur, berani bertindak, dapat dipercaya, dan hormat kepada oranglain (Pusat Kurikulum,2010). Dalam kamus besar bahasa Indonesia tidak memuat kata karakter, namun yang ada adalah bermakna sebagai bawaan, hati, jiwa, kepribadian, berperilaku, tabiat, dan kata 'watak' dalam arti sifat batin manusia yang mempengaruhi segenap pikiran dan tingkah lakunya (Pusat Bahasa,2005). Watak menurut Soedarsono (2004) dapat diubah. Watak merupakan pemicu atau pemberi "arah" atas tindakan-tindakan perilaku seseorang.

Karakter baik berarti individu memiliki pengetahuan tentang potensi dirinya, yang ditandai dengan nilai-nilai seperti reflektif, 
percaya diri, rasional, logis, kritis, analitis, kreatif dan inovatif, mandiri, hidup sehat, bertanggungjawab, cinta ilmu, sabar, berhatihati, rela berkorban, pemberani, dapat dipercaya, jujur, menepati janji, adil, rendah hati, malu berbuat salah, pemaaf, berhati lembut, setia, bekerja keras, tekun, ulet/gigih, teliti, berinisiatif, berpikir positif, disiplin, antisipatif, inisiatif, visioner, bersahaja, bersemangat, dinamis, hemat/efisien, menghargai waktu, pengabdian/dedikatif, pengendalian diri, produktif, ramah, cinta keindahan (estetis), sportif, tabah, terbuka, dan tertib.

Individu yang berkarakter terbaik merupakan seseorang yang berusaha melakukan hal-hal yang terbaik terhadap Tuhan YME, dirinya, sesamanya, lingkungannya, bangsa dan negaranya serta dunia internasional pada umumnya dengan mengoptimalkan potensi (pengetahuan) dirinya dan disertai dengan kesadaran, emosi dan motivasinya serta perasaannya. Seseorang yang dapat dipercaya, bertanggungjawab, hormat, adil, peduli, empati, mengendalikan diri, dan, di atas segalanya, dia adalah warga negara yang berkarakter baik yang mematuhi hukum dan bermain menurut aturan. Karakter yang baik terdiri dari mengetahui yang baik, menginginkan yang baik, dan melakukan yang baik (Lickona, 1992).

Pengertian-pengertian tersebut, dapat dikatakan bahwa karakter adalah nilai-nilai yang khas-baik (tahu nilai kebaikan, mau berbuat baik, nyata berkehidupan baik, dan berdampak baik terhadap lingkungan) yang terpateri dalam diri dan terejawantahkan dalam perilaku. Karakter berkaitan dengan sikap, pola perilaku dan atau kebiasaan yang mempengaruhi interaksi seseorang terhadap Tuhan dan lingkungannya. Karakter menentukan sikap, perkataan dan tindakan. Hampir setiap masalah dan kesuksesan yang dicapai seseorang ditentukan oleh karakter yang dimiliki. Karakter secara koheren memancar dari hasil olah pikir, olah hati, olahraga, serta olah rasa dan karsa seseorang atau sekelompok orang. Karakter merupakan ciri khas seseorang atau sekelompok orang yang mengandung nilai, kemampuan, kapasitas moral, dan ketegaran dalam menghadapi kesulitan dan tantangan (PemerintahRI, 2010). 
Sementara itu, menurut Suyanto karakter adalah cara berpikir dan berperilaku yang menjadi ciri khas tiap individu untuk hidup dan bekerja sama, baik dalam lingkup keluarga, masyarakat, bangsa dan negara. Individu yang berkarakter baik adalah individu yang bisa membuat keputusan dan siap mempertanggungjawabkan tiap akibat dari keputusan yang ia buat. Selanjutnya, masih menurut Suyanto, terdapat sembilan pilar karakter yang berasal dari nilainilai luhur universal, yaitu:1) karakter cinta Tuhan dan segenap ciptaan-Nya; 2) kemandirian dan tanggung jawab; 3) kejujuran/ amanah, diplomatis; 4) hormat dan santun; 5) dermawan, suka tolong-menolong dan gotong royong/kerja sama; 6) percaya diri dan pekerja keras; 7) kepemimpinan dan keadilan; 8) baik dan rendah hati, dan; 9) karakter toleransi, kedamaian, dan kesatuan.

Bagi Foerster, dalam Grandiosa karakter merupakan sesuatu yang mengualifikasi seorang pribadi. Karakter menjadi identitas yang mengatasi pengalaman kontingen yang selalu berubah. Dari kematangan karakter inilah, kualitas seorang pribadi diukur. Interaksi seseorang dengan orang lain menumbuhkan karakter masyarakat. Karakter adalah 'distinctive trait, distinctive quality, moral strength, the pattern of behavior found in an individual or group' (Peterson dan Seligman, 2004; Neufeld,1991). Oleh karena itu, pengembangan karakter hanya dapat dilakukan melalui pengembangan karakter pribadi seseorang.

Dari beberapa pengertian diatas secara umum dapat dimaknai bahwa karakter merupakan nilai-nilai perilaku manusia yang baik yang berhubungan dengan Tuhan Yang Maha Esa, dirisendiri, sesama manusia, lingkungan, dan kebangsaan yang terwujud dalam pikiran, sikap, perasaan, perkataan, dan perbuatan berdasarkan norma-norma agama, hukum, tata krama, budaya, dan adat istiadat. Karenanya, karakter dikaitkan dengan sifat khas atau istimewa, atau kekuatan moral, atau pola tingkah laku seseorang. Pembentukan karakter merupakan salah satu tujuan pendidikan nasional. Dalam Pasal 1 UU Sisdiknas tahun 2003 dinyatakan bahwa diantara tujuan pendidikan nasional adalah mengembangkan potensi siswa untuk memiliki kecerdasan, kepribadian dan akhlak mulia. Amanah 
peraturan perundang-undangan itu bermaksud agar pendidikan tidak hanya membentuk insan Indonesia yang cerdas, namun juga berkepribadian atau berkarakter, sehingga nantinya akan lahir generasi bangsa yang tumbuh berkembang dengan karakter yang bernafas nilai-nilai luhur bangsa serta agama. Pendidikan yang bertujuan melahirkan insan cerdas dan berkarakter kuat itu, juga pernah dikatakan Martin Luther King dalam Suyanto, yakni; intelligence plus character... that is the goal of true education (kecerdasan yang berkarakter yaitu tujuan akhir pendidikan yang sebenarnya).

\section{c. Analisis High Order Thinking Skill dalam pembentukan karakter siswa sekolah dasar}

Pemerintah mengharapkan para siswa mencapai berbagai kompetensi dengan penerapan HOTS atau Keterampilan Bepikir Tingkat Tinggi. Kompetensi tersebut yaitu berpikir kritis (criticial thinking), kreatif dan inovasi (creative and innovative), kemampuan berkomunikasi (communication skill), kemampuan bekerja sama (collaboration) dan kepercayaan diri (confidence). Lima hal yang disampaikan pemerintah yang menjadi target karakter siswa itu melekat pada sistem evaluasi kita dalam ujian nasional dan merupakan kecakapan di era industri 4.0.

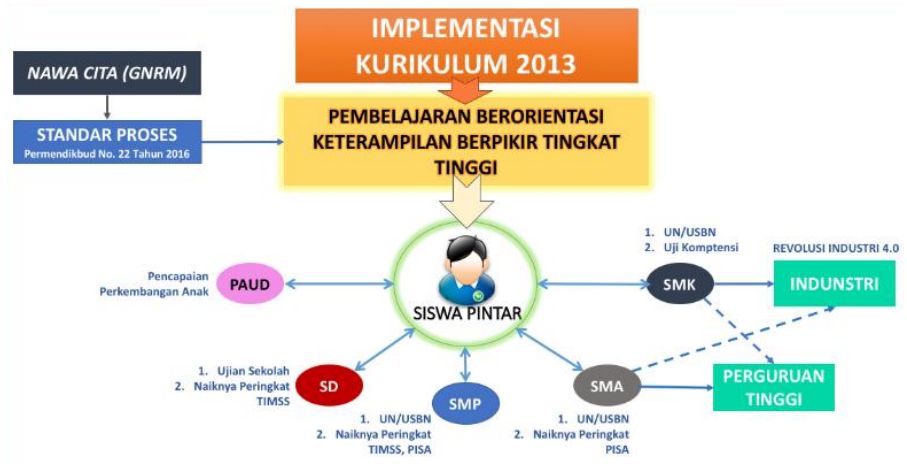

Gambar 1. Grand Desain Pembelajaran Berorientasi pada HOTS.

Higher Order Thinking Skill (HOTS) dipicu oleh empat kondisi.

1) Sebuah situasi belajar tertentu yang memerlukan strategi pembelajaran yang spesifik dan tidak dapat digunakan di situasi belajar lainnya. 
2) Kecerdasan yang tidak lagi dipandang sebagai kemampuan yang tidak dapat diubah, melainkan kesatuan pengetahuan yang dipengaruhi oleh berbagai faktor yang terdiri dari lingkungan belajar, strategi dan kesadaran dalam belajar.

3) Pemahaman pandangan yang telah bergeser dari unidimensi, linier, hirarki atau spiral menuju pemahaman pandangan ke multidimensi dan interaktif.

4) Keterampilan berpikir tingkat tinggi yang lebih spesifik seperti penalaran, kemampuan analisis, pemecahan masalah, dan keterampilan berpikir kritis dan kreatif.

Pembelajaran era industri 4.0 menggunakan istilah yang dikenal sebagai 4Cs (critical thinking, communication, collaboration, and creativity) adalah empat keterampilan yang telah diidentifikasi sebagai keterampilan era industri 4.0 sebagai keterampilan sangat penting dan diperlukan siswa untuk menumbuhkan karakter.

Tabel 4. Peta kompetensi keterampilan 4Cs

\begin{tabular}{|c|c|}
\hline Keterampilan $4 \mathrm{Cs}$ & Kompetensi \\
\hline Creativity Thinking and innovation & $\begin{array}{l}\text { Siswa dapat menghasilkan, } \\
\text { mengembangkan, dan } \\
\text { mengimplementasikan ide-ide mereka } \\
\text { secara kreatif baik secara } \\
\text { mandiri maupun berkelompok. }\end{array}$ \\
\hline Critical Thinking and Problem Solving & $\begin{array}{l}\text { Siswa dapat mengidentifikasi, } \\
\text { menganalisis, menginterpretasikan, dan } \\
\text { mengevaluasi bukti-bukti, argumentasi, } \\
\text { klaim dan data-data yang tersaji } \\
\text { secara luas melalui pengakajian secara } \\
\text { mendalam, serta merefleksikannya dalam } \\
\text { kehidupan seharihari. }\end{array}$ \\
\hline Communication & $\begin{array}{l}\text { Siswa dapat mengkomunikasikan ide-ide } \\
\text { dan gagasan secara efektif menggunakan } \\
\text { media lisan, tertulis, maupun teknologi. }\end{array}$ \\
\hline Collaboration & $\begin{array}{l}\text { Siswa dapat bekerja sama dalam } \\
\text { sebuah kelompok dalam memecahkan } \\
\text { permsalahan yang ditemukan }\end{array}$ \\
\hline
\end{tabular}

Elementary Vol. 7 No. 2 Juli-Desember 2019 
berdasarkan hasil kajian dokumen pada UU Sisdiknas, Nawacita, dan RPJMN Pendidikan Dasar, Menengah, dan Tinggi, diperoleh 2 standar tambahan sesuai dengan kebijakan Kurikulum dan kebijakan Pemerintah, yaitu sesuai dengan Penguatan Pendidikan Karakter pada Pengembangan Karakter (Character Building) dan Nilai Spiritual (Spiritual Value). Secara keseluruhan standar di Indonesia ini dirumuskan menjadi Indonesian Partnership for 21 Century Skill Standard (IP-21CSS).

Tabel 5. Indonesian Partnership for 21 Century Skill Standard

\begin{tabular}{|c|c|c|}
\hline Keterampilan & IP-21CSS & Aspek \\
\hline Creativity & \multirow{9}{*}{$4 \mathrm{Cs}$} & - Berpikir secara kreatif \\
\hline Thinking and & & - Bekerja kreatif dengan lainnya \\
\hline innovation & & - Mengimplementasikan inovasi \\
\hline Critical Thinking & & - Penalaran efektif \\
\hline and Problem & & - Menggunakan sistem berpikir \\
\hline Solving & & - Membuat penilaian dan keputusan \\
\hline & & - Memecahkan masalah \\
\hline \multirow{2}{*}{$\begin{array}{l}\text { Communication } \\
\text { and Collaboration }\end{array}$} & & - Berkomunikasi secara jelas \\
\hline & & - Berkolaborasi dengan orang lain \\
\hline \multirow{4}{*}{$\begin{array}{l}\text { Information, Media } \\
\text { and Technology } \\
\text { Skills }\end{array}$} & \multirow{4}{*}{ ICTs } & - Mengakses dan mengevaluasi informasi \\
\hline & & - Menggunakan dan menata informasi \\
\hline & & - Menganalisis dan menghasilkan media \\
\hline & & - Mengaplikasikan teknologi secara efektif \\
\hline \multirow[t]{6}{*}{ Life \& Career Skills } & \multirow{4}{*}{$\begin{array}{l}\text { Character } \\
\text { Building }\end{array}$} & - Siswa \\
\hline & & $\begin{array}{l}\text { - jujur, teliti, terbuka dan penuh kehati- } \\
\text { hatian) }\end{array}$ \\
\hline & & $\begin{array}{l}\text { - Menunjukkan penerimaan terhadap nilai } \\
\text { moral yang }\end{array}$ \\
\hline & & - berlaku di masyarakat \\
\hline & \multirow{2}{*}{$\begin{array}{l}\text { Spiritual } \\
\text { Values }\end{array}$} & $\begin{array}{l}\text { - Menghayati konsep ke-Tuhanan melalui } \\
\text { ilmu pengetahuan }\end{array}$ \\
\hline & & $\begin{array}{l}\text { - Menginternalisasikan nilai-nilai spiritual } \\
\text { dalam kehidupan } \\
\text { - sehari-hari }\end{array}$ \\
\hline
\end{tabular}

Dengan menggunakan pembelajaran keterampilan 4Cs dalam keterampilan berpikir tingkat tinggi dapat menumbuhkan dan mengembangkan karakte siswa secara maksimal sesuai dengan tujuan pendidikan nasional. 


\section{Simpulan}

Berdasarkan pembahasan yang telah diuraikan pada bab sebelumnya, maka simpulan dari penelitian ini sebagai berikut:

1. Higher Order Thinking Skill (HOTS) adalah proses berpikir yang menuntut pemikiran secara kritis, kreatif, analitis terhadap informasi dan data dalam memecahkan permasalahan melibatkan aktivitas mental yang paling dasar. Higher Order Thinking Skill (HOTS) erat kaitannya dengan keterampilan berpikir sesuai dengan ranah kognitif, afektif, dan psikomotor yang menjadi satu kesatuan dalam proses belajar dan mengajar

2. Karakter adalah cara berpikir dan berperilaku yang menjadi ciri khas tiap individu untuk hidup dan bekerja sama, baik dalam lingkup keluarga, masyarakat, bangsa dan Negara dengan menanamkan 1) karakter cinta Tuhan dan segenap ciptaanNya; 2) kemandirian dan tanggung jawab; 3) kejujuran/amanah, diplomatis; 4) hormat dan santun; 5) dermawan, suka tolong-menolong dan gotong royong/kerja sama; 6) percaya diri dan pekerja keras; 7) kepemimpinan dan keadilan; 8) baik dan rendah hati, dan; 9) karakter toleransi, kedamaian, dan kesatuan.

3. Penerapan HOTS di era industri 4.0 menggunakan Pembelajaran 4Cs (critical thinking, communication, collaboration, and creativity) adalah empat keterampilan yang telah diidentifikasi untuk menumbuhkan karakter pada siswa sekolah dasar. 


\section{DAFTAR PUSTAKA}

Afandi \& Sajidan. Stimulasi Keterampilan Tingkat Tinggi. UNSPRESS. 2017.

Albertus, Doni Koesoema. Pendidikan Karakter Utuh dan Menyeluruh. Yogyakarta: Kanisius. 2015.

Kementerian Pendidikan Nasional.. Pengembangan Pendidikan Budaya dan Karakter Bangsa: Pedoman Sekolah. Ja- karta: Badan Penelitian dan Pengembangan Pusat Kurikulum. 2010

King, F.J., Goodson, L., \& Rohani. Higher Order Thinking Skills. Center for Advancement of Learning and Assessment, 2006.

Lickona, Thomas. Educating for Character,How Our Schools Can Teach Respect and Responsibility. New York: Bantam Books. 1991.

Maya Bialik \& Charles Fadel.. Skills for the 21st Century: What Should Students Learn?. Center for Curriculum Redesign Boston, Massachusetts, 2015

Samani, Muclas dan Hariyanto. Konsep dan Model Pendidikan Karakter. Bandung: Remaja Rosdakarya. 2011.

Suryaman, Maman. "Pendidikan Karakter Melalui Pembelajaran Sastra". Dalam Cakrawala Pendidikan, Tahun XXIX.Vol. 1 No. 3. 2010 Edisi Khusus Dies Natalis UNY. 2010.

Triatmanto. "Tantangan Implementasi Pendidikan Karakter Di Sekolah." Cakrawala Pendidikan. Tahun XXIX.Vol. 1 No. 3. 2010 Edisi Khusus Dies Natalis UNY. 2010.

Undang-Undang Republik Indonesia Nomor 20 Tahun 2003 tentang Sistem Pendidikan Nasional. 